P. R. Okamoto ${ }^{a}$, J. Heuer ${ }^{a, c}$, N. Q. Lam ${ }^{a}$,

S. Ohnukib, Y. Matsukawab, K. Tozawa ${ }^{b}$, and J. F. Stubbins ${ }^{c}$

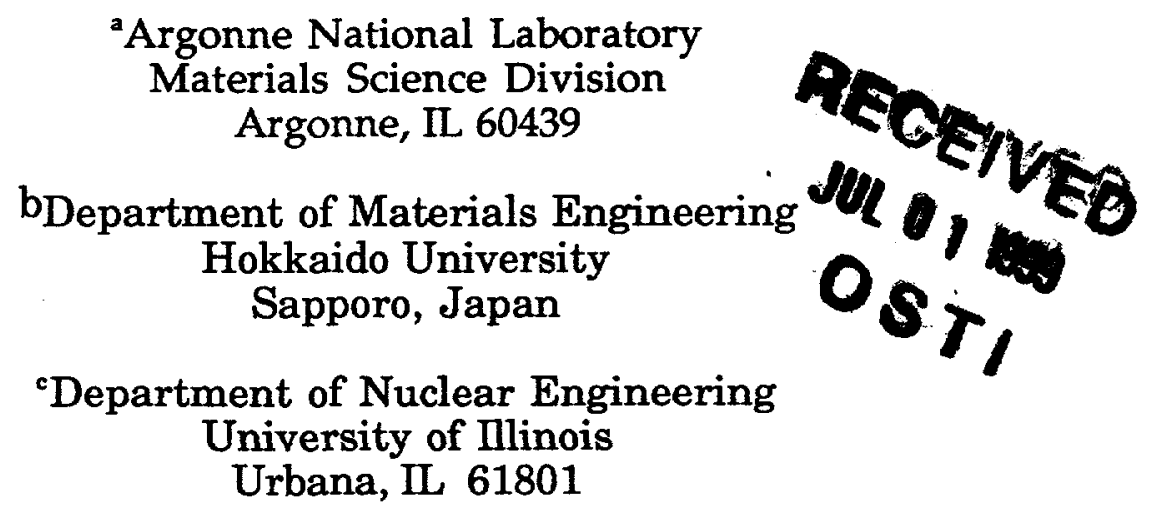

December 1997

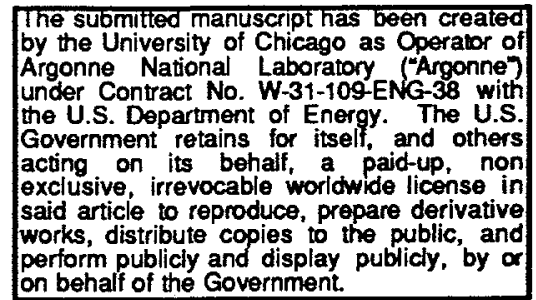

Manuscript to be presented at the Materials Research Society, Boston, MA, December 1-5, 1997.

*Work supported by the U.S. Department of Energy, Basic Energy SciencesMaterials Sciences, under contract No. W-31-109-Eng-38. 


\section{DISCLAIMER}

This report was prepared as an account of work sponsored by an agency of the United States Government. Neither the United States Government nor any agency thereof, nor any of their employees, make any warranty, express or implied, or assumes any legal liability or responsibility for the accuracy, completeness, or usefulness of any information, apparatus, product, or process disclosed, or represents that its use would not infringe privately owned rights. Reference herein to any specific commercial product, process, or service by trade name, trademark, manufacturer, or otherwise does not necessarily constitute or imply its endorsement, recommendation, or favoring by the United States Government or any agency thereof. The views and opinions of authors expressed herein do not necessarily state or reflect those of the United States Government or any agency thereof. 


\section{DISCLAIMER}

Portions of this document may be illegible in electronic image products. Images are produced from the best available original document. 


\title{
STRESS-INDUCED AMORPHIZATION AT MOVING CRACK TIPS IN NiTi
}

\author{
P. R. Okamoto ${ }^{1}$, J. K. Heuer ${ }^{1,3}$, N. Q. Lam ${ }^{1}$, S. Ohnuki ${ }^{2}$, Y. Matsukawa ${ }^{2}$, K. Tozawa ${ }^{2}$, \\ and J. F. Stubbins ${ }^{3}$ \\ ${ }^{1}$ Materials Science Division, Argonne National Laboratory, Argonne, Il 60439 \\ ${ }^{2}$ Department of Materials Engineering, Hokkaido University, Sapporo, Japan \\ ${ }^{3}$ Department of Nuclear Engineering, University of Illinois, Urbana, IL 61801
}

\section{ABSTRACT}

In situ fracture studies on thin-film NiTi intermetallic compounds have been carried out in the high-voltage electron microscope at Argonne National Laboratory. Local stress-induced amorphization of regions directly in front of moving crack tips has been observed under tensile loading conditions. The stress-induced amorphization at crack tips exhibits a temperature dependence similar to that of ion-induced amorphization of NiTi. The upper limiting temperature for stress-induced amorphization is the same as that for ion-induced amorphization of crystalline NiTi and for amorphous phase formation during ion-beam mixing of $\mathrm{Ni}$ and $\mathrm{Ti}$ multilayer specimens. This upper limiting temperature of $600 \mathrm{~K}$ is also the lowest temperature at which stress-induced amorphous phase crystallizes during isothermal annealing. This isothermal crystallization temperature is nearly $200 \mathrm{~K}$ less than the kinetic crystallization temperature during heating of unrelaxed NiTi glasses formed by rapid quenching or vapor phase deposition.

\section{INTRODUCTION}

Despite a long and continuing effort to understand why and how solids fracture, no generally accepted theory of the phenomenon has yet been developed. Although the local stress intensification in the immediate vicinity of the crack tip is known to be the primary driving force

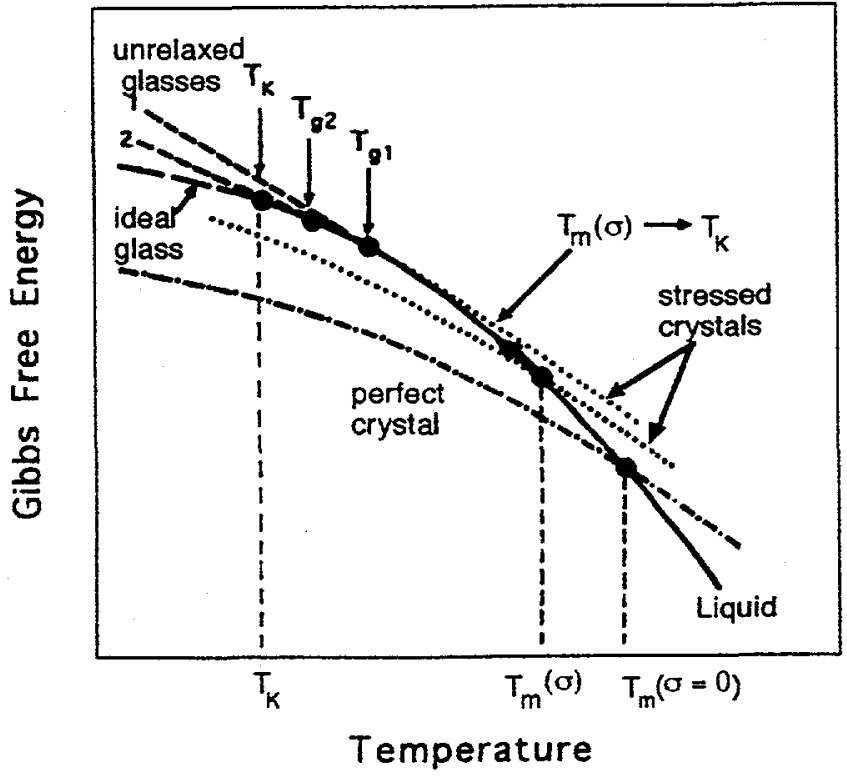

Fig. 1. Gibbs free energy versus temperature of the stressed and unstressed crystals. for fracture, the mechanism by which the strain energy stored in crack tip is dissipated during propagation is not well understood. An intriguing question is whether the strain energy can be released via local melting of the crack tip. This possibility is suggested by recent Monte Carlo (MC) simulations which show that fcc elemental crystals under uniaxial tension can undergo stress-induced melting at temperatures $T_{m}(\sigma)$ well below the thermodynamic melting temperature $T_{m}(\sigma=0)$ of the unstressed crystal [1]. For a given temperature, $\mathrm{T}<\mathrm{T}_{\mathrm{m}}(\sigma=0)$, this stress-induced melting occurs at a critical stress where the free energy of the stressed crystal becomes equal to that of the supercooled liquid. This is illustrated schematically in Fig. 1, which shows the temperature dependence of the Gibbs free energy of the unstressed crystal, of the liquid, and of two stressed crystalline states 
indicated by the dotted curves. Also shown are: (i) the ideal glass [2], which has the same entropy as that of the perfect crystal, and (ii) two unrelaxed glassy states 1 and 2 , associated with cooling rates such that $T_{g 1}>T_{g 2}$. $T_{K}$ is the glass transition temperature of the ideal glass as defined by Kauzmann [2].

Although the MC results clearly show that stress-induced melting occurs below $\mathrm{T}_{\mathrm{m}}(\sigma=0)$ for a simple fcc metal $(\mathrm{Pt})$, they also show, equally clearly, that the melting process is a transient phenomenon which will be difficult, if not impossible, to observe directly since the liquified crack tip region (which cannot sustain a load) immediately crystallizes as the crack propagates, leaving no evidence that melting has occurred. However, at very low temperatures ( $\left.T<\mathrm{T}_{\mathrm{K}}\right)$, it may be possible to observe the phenomenon in an intermetallic compound as a stress-induced crystal-to-glass transformation (C-G) that results in the formation of the ideal glass [3]. This possibility is illustrated schematically in Fig. 1, which shows that the glassy state with the lowest Gibbs free energy, i.e., the ideal glass, will be the first glassy state to be reached from below via any disorder-driven $C-G$ transition. Hence, the same unique ideal glassy state should be obtained whether the transformation is driven by irradiation, ion mixing, or applied stresses. Here, we report direct observations of stress-induced amorphization at moving crack tips during straining of the intermetallic compound NiTi. The temperature dependence of stress-induced amorphization and the isothermal crystallization behavior of the resulting glass are compared with those associated with irradiation-induced amorphization of $\mathrm{NiTi}$ [4]. As will be shown, the results confirm the hypothesis that, like other solid-state amorphizing transformations, stress-induced C-A transformations lead to the formation of the ideal glassy state [3].

\section{EXPERIMENTAL PROCEDURES}

In situ fracture observations in NiTi were carried out with a Gatan side-entry heatingstraining stage in the high-voltage transmission electron microscope (HVEM) at the Argonne National Laboratory HVEM-Tandem accelerator facilities. The straining stage is capable of achieving temperatures between $300-825 \mathrm{~K}$ and a maximum elongation of $2000 \mu \mathrm{m}$. Miniature $\mathrm{NiTi}$ tensile specimens were prepared from bulk alloys with Ti concentrations between $47-49$ at. \% Ti. The bulk alloys were rolled down to $100 \mu \mathrm{m}$ thick sheets which were subsequently cut into $3.0 \times 6.5 \mathrm{~mm}$ strips. Tensile specimens for the Gatan straining stage were prepared from these strips by boring $1.0-\mathrm{mm}$ diameter holes in the two ends for mounting on the straining stage. A gauge length was created by electro-etching two slits along the length of the specimen. All specimens were given a high-vacuum, pre-strain anneal at $900^{\circ} \mathrm{C}$ for 20 minutes to remove any mechanical damage introduced during preparation. The annealing treatment resulted in polycrystalline austenitic NiTi (B2 structure) with a typical grain size of $10 \mu \mathrm{m}$. Prior to mounting, the central area in the gauge length was electropolished to electron transparency, using a single-jet electropolisher with custom polishing holder.

\section{TEMPERATURE DEPENDENCE OF STRESS-INDUCED AMORPHIZATION}

In situ studies of stress-induced amorphization at crack tips on NiTi tensile specimens were carried out between $300-750 \mathrm{~K}$. Figure 2 shows a dark-field (DF) image of a typical crack formed during straining at $300 \mathrm{~K}$, which is well below the range of kinetic glass transition temperature $750-850 \mathrm{~K}$ reported for amorphous NiTi produced by rapid quenching techniques [5]. Selected area diffraction (SAD) patterns taken from areas away from the crack tip region indicate a crystalline structure while the SAD pattern from the crack tip region exhibits diffuse intensity halos, indicating that an amorphous phase forms ahead of the crack tip. DF images taken with part of the first diffuse intensity halo show that the amorphous phase is also present 


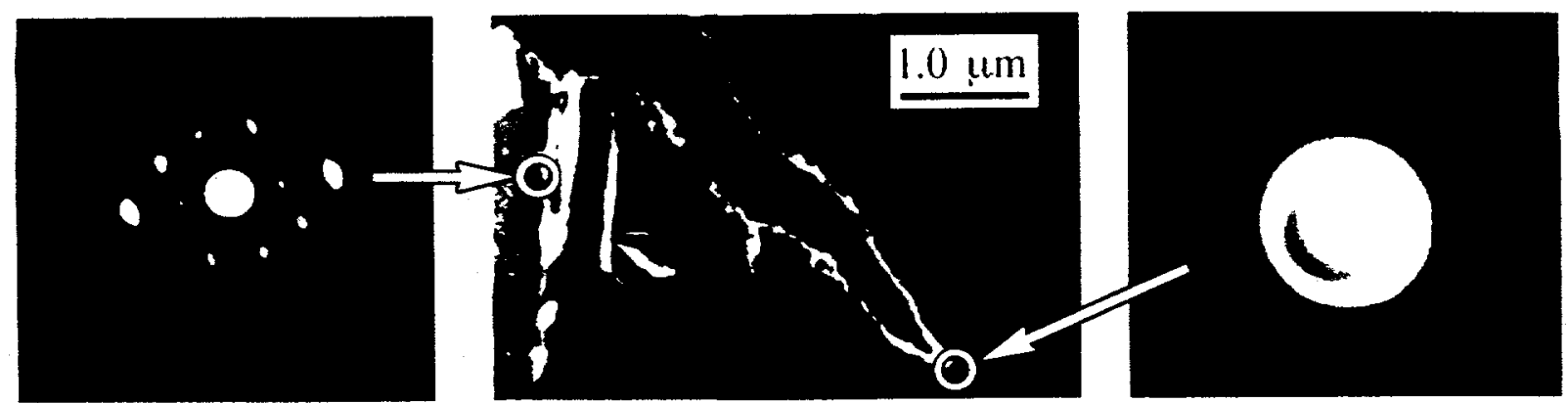

Fig. 2. Dark-field image and selected area diffraction patterns showing amorphous phase formation in the region ahead of crack tip and along the crack edges.

along the edges of the crack as well as in the region ahead of the crack tip itself. This indicates that, at $300 \mathrm{~K}$, the amorphous phase which forms at the crack tip remains amorphous as the crack propagates into the crystal.

The temperature dependence of stress-induced amorphization is summarized in Fig. 3, which shows the average width of the amorphous layer along the crack edges as a function of temperature measured for several NiTi specimens having either the B2 or martensitic structure prior to straining. These results show that stress-induced amorphization at crack tips only occurs for temperatures below about $600 \mathrm{~K}$. As shown in Fig. 4, this cutoff temperature can also be determined in a different way by plotting the percentage of specimens (12 were examined) which exhibit either complete or partial stress-induced amorphization as a function of straining temperature. Again, one sees a relatively sharp upper-limiting cutoff temperature at about $600 \mathrm{~K}$, which is also the upper-limiting cutoff temperature for irradiation-induced amorphization of crystalline NiTi by heavy-ions [4], and for amorphous phase formation by ion-beam mixing of $\mathrm{Ni}$ and $\mathrm{Ti}$ multilayer specimens [6]. $600 \mathrm{~K}$ is also the lower-limiting cutoff temperature, $\mathrm{T}_{\mathrm{A}-\mathrm{C}}$, for the reverse transformation of irradiation-induced amorphous-to-crystalline transformation.

The thermodynamic significance of the cutoff temperature is that $T_{A-C}=T_{K}$, the ideal glass transition temperature [3]. That $\mathrm{T}_{\mathrm{K}}$ must be the upper-limiting cutoff temperature for all solidstate amorphization follows from the fact that a thermodynamic driving force for amorphization exists only for metastable crystalline states that have free energies higher than that of the ideal glass. As seen in Fig. 1 for the case of stress-induced amorphization, this thermodynamic criterion for amorphization will be satisfied only when $T_{m}(\sigma) \leq T_{K}$. Hence, like other $C-G$ transformations. stress-induced amorphization cannot occur for $T>T_{K}$. However, stressinduced melting to a supercooled liquid can occur above $T_{K}$, provided no relaxation of the stressed state occurs

\section{CRYSTALLIZATION BEHAVIOR OF STRESS-INDUCED AMORPHOUS PHASES}

The ideal glass transition temperature can also be determined by plotting the kinetic glass transition and crystallization temperatures as a function of heating rate. As shown by Busch et al. [7] for amorphous $\mathrm{Zr}_{41.2} \mathrm{Ti}_{1}{ }_{\xi} \mathrm{Cu}_{12.5} \mathrm{Ni}_{10.0} \mathrm{Be}_{22 . .5}$ and by Okamoto et al. [3] for amorphous CuTi, the two curves, $T_{g}$ and $T_{x}$, intersect at $T_{K}=562$ and $565 \mathrm{~K}$, respectively, for critical heating rates of $1.67 \times 10^{-5} \mathrm{~K} / \mathrm{min}$ and $6.6 \times 10^{-1} \mathrm{~K} / \mathrm{min}$. These heating rates correspond to $1 \mathrm{~K}$ every 41 days for 


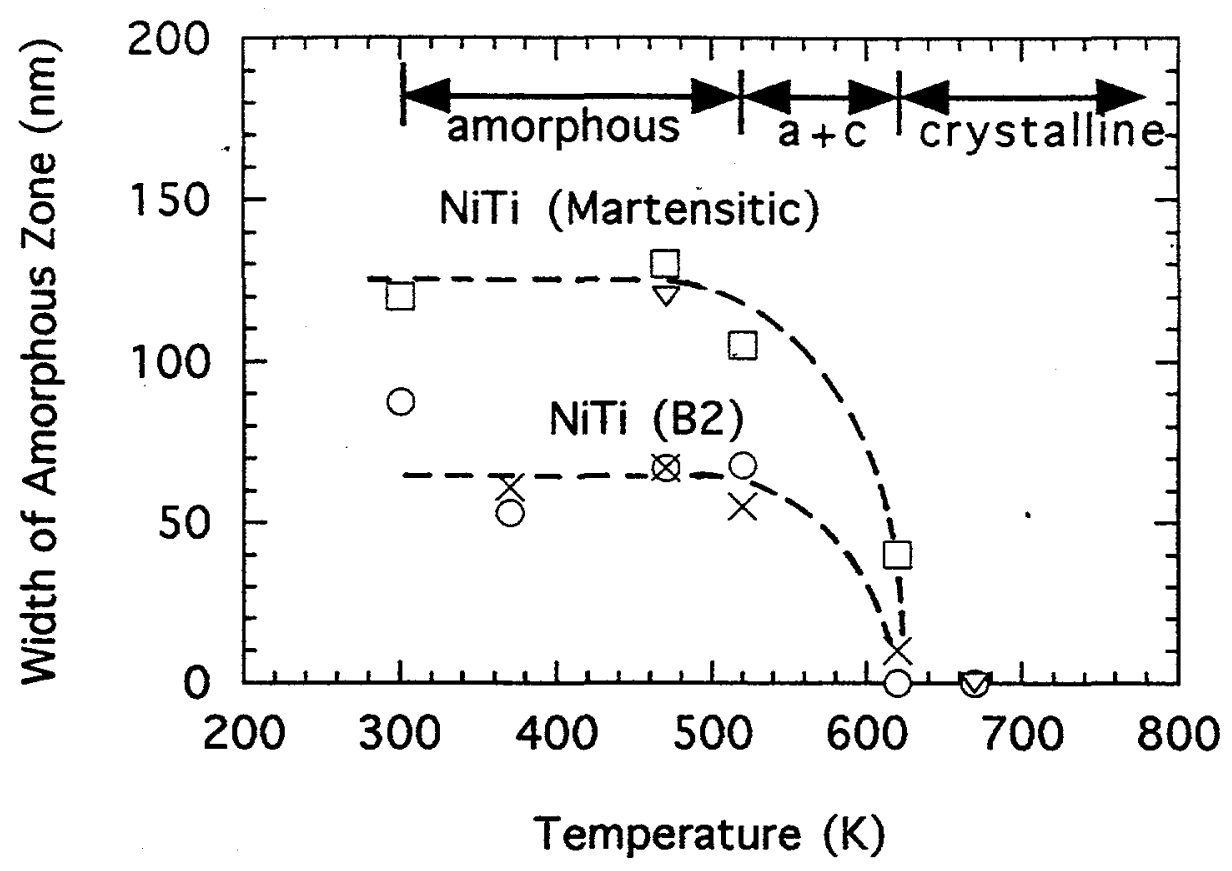

Fig. 3. Average width of amorphous zone along crack edge as a function of temperature for B2 and martensitic NiTi.

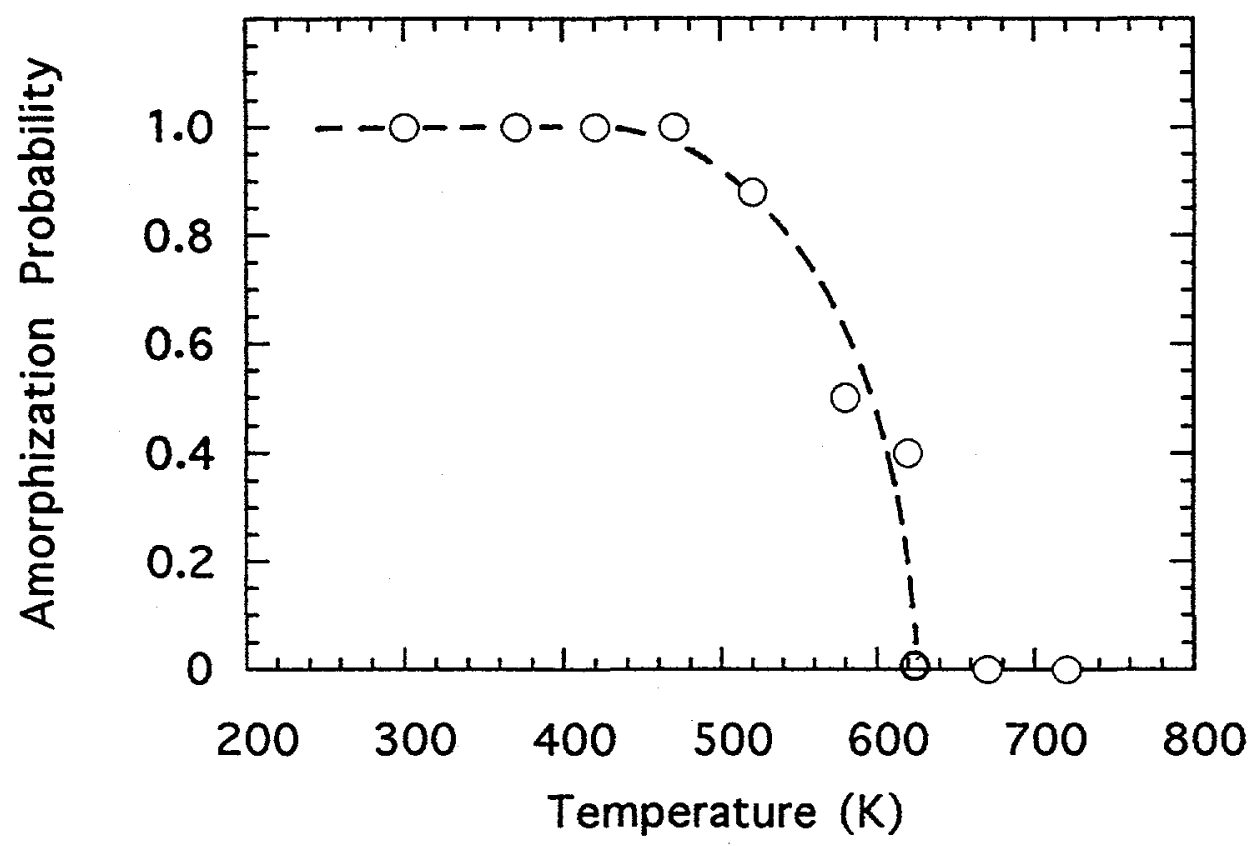

Fig. 4. Percentage of NiTi specimens exibiting either complete or partial amorphization during fracture. 

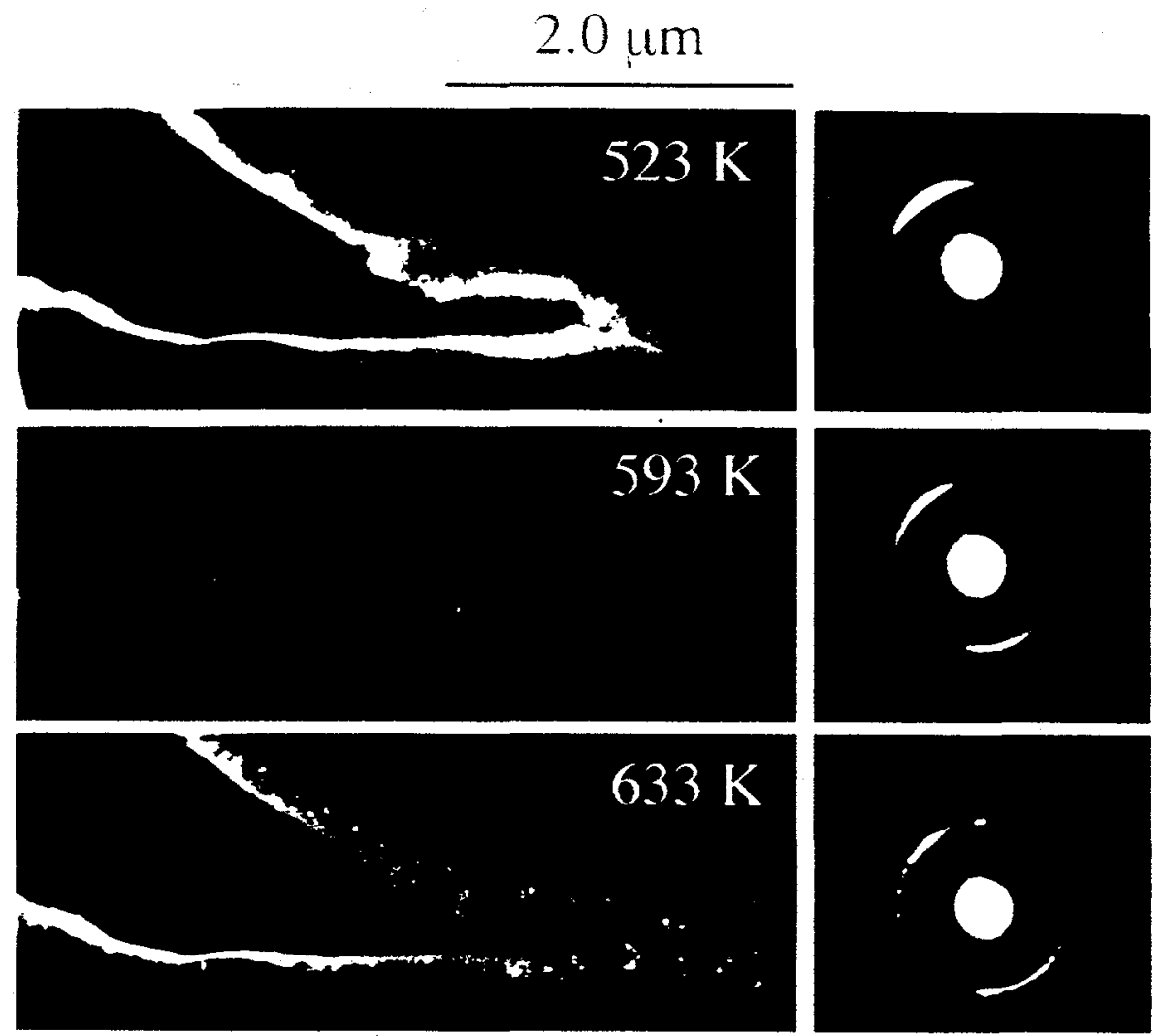

Fig. 5. Annealing of stress-induced amorphous phase at an intergranular crack in NiTi formed during straining in the HVEM at $300 \mathrm{~K}$. The specimen was annealed for 15 minutes at each temperature.

amorphous $\mathrm{Zr}_{+1.2} \mathrm{Ti}_{13.8} \mathrm{Cu}_{12.5} \mathrm{Ni}_{10.0} \mathrm{Be}_{22.5 .5}$ and $1 \mathrm{~K}$ every 25.3 hours for amorphous $\mathrm{CuTi}$, which means essentially isothermal annealing conditions. Hence, since $T_{K}=T_{X}=T_{A \cdot c}$ for these essentially zero heating rates, the ideal glass should crystallize when annealed isothermally at $T_{K}$, even though it is typically several hundreds of degrees lower than the kinetic crystallization temperatures observed during rapid heating of the unrelaxed glasses. This hypothesis was confirmed by annealing a specimen fractured at $300 \mathrm{~K}$ for 15 minutes at various temperatures between 300 and $923 \mathrm{~K}$. No change in the structure of the amorphous NiTi occurs until 593K where the first hint of crystallization is observed. This is illustrated in Fig. 5, which shows DF images and the corresponding SAD patterns after annealing at 523,593 and $633 \mathrm{~K}$. At $523 \mathrm{~K}$, the SAD pattern shows that the crack tip is still completely amorphous. At $593 \mathrm{~K}$, a few small grains form at the crack tip and along its edges, although the SAD pattern indicates that these regions are still primarily amorphous after annealing for 15 minutes. At $633 \mathrm{~K}$, however, the SAD pattern exhibits polycrystalline rings, indicating that the crack tip is almost completely polycrystalline. The DF image shows many more fine grains at the crack tip and along its edges.

\section{CONCLUSIONS}

In situ fracture studies of crystalline $\mathrm{NiTi}$ strongly support recent $\mathrm{MC}$ simulations results which show that a transient stress-induced melting at crack tips can lead to failure by cavity formation. The stress-induced melting occurs at a critical stress where the free energy of the stressed crystal becomes equal to that of the supercooled liquid. The melting process will be difficult to observe in simple metals since immediate recrystallization of the liquified crack tip 
region upon cavity formation leaves no evidence that melting has occurred. However, at low temperatures $\left(T \leq T_{K}\right)$, the phenomenon can be directly observed in crystalline NiTi as a stressinduced amorphization of the moving crack tip. Moreover, both the temperature dependence and annealing behavior of stress-induced amorphous NiTi exhibit all the characteristic features expected of the ideal glass. As the glass with the lowest free energy, its formation at temperatures below $T_{K}$, where long-range diffusion is suppressed, can be understood as the most energetically-favored, kinetically-constrained response of crystalline alloys driven far from equilibrium by applied stresses and/or radiation damage.

\section{ACKNOWLEDGMENTS}

This work was supported by the U.S. Department of Energy, Basic Energy SciencesMaterials Sciences, under contract W-31-109-Eng-38. Special thanks are extended to B. Kestel for his aid with tensile specimen preparation, and to E. Ryan, S. Ockers and L. Funk of the Argonne HVEM-Tandem accelerator facility for their assistance in performing the in situ straining experiments.

\section{REFERENCES}

1. R. M. Lynden-Bell, J. Phys.: Condens. Matter 7, 4603 (1995).

2. W. Kauzmann, Chem. Rev. 43, 219 (1948).

3. P. R. Okamoto, N. Q. Lam, and L. E. Rehn, "Physics of Crystal-to-Glass Transformations", to be published in Solid State Physics (H. Ehrenreich and F. Spaepen, eds.), 1998.

4. P. Moine and C. Jaouen, J. Alloys Compounds 194, 373 (1993).

5. K. H. J. Buschow, J. Appl. Phys. 56, 304 (1984).

6. L-U. Aaen Andersen, J. Bottinger, J. Janting and N. Karpe, Mater. Sci. Eng. A134, 1255 (1991).

7. R. Busch, Y. J. Kim, and W. L. Johnson, J. Appl. Phys. 77, 4039 (1995). 